\title{
Evaluation of Different Treatment Modules for Respiratory Distress Syndrome in Preterm Neonates
}

\author{
Rajeev kumar Mittal, ${ }^{1}$ S. P. Goyal, ${ }^{2}$ P. K. Gupta ${ }^{3}$ \\ ${ }^{1}$ Pediatrician (Scholar), Department of Pediatrics, Subharti Medical College, Meerut, ${ }^{2}$ Ex Professor, Department of Pediatrics, Subharti Medical College, Meerut, ${ }^{3} \mathrm{HOD}$, \\ Department of Pediatrics, Subharti Medical College, Meerut.
}

\section{Abstract}

Background: RDS is mainly caused by a lack of a slippery substance in the lungs called surfactant. This substance helps the lungs fill with air and keeps the air sacs from deflating. Present study is to assess the difference between intravenous and inhalational ambroxol in prevention of respiratory distress syndrome in preterm infants. Subjects and Methods: Out of those 56 were assigned under group A i.e. being treated with intravenous ambroxol and others were assigned under group B i.e. being treated by atomizing or inhalational ambroxol. The intravenous group was injected with $15 \mathrm{mg} / \mathrm{kg}$ ambroxol in umbilical vein immediately after birth followed by intravenous infusion of ambroxol $30 \mathrm{mg} / \mathrm{kg}$ for 2 days. Results: Early administration of either intravenous or atomizing ambroxol can produce a positive efficacy for the prevention of RDS in preterm infants but inhalation or atomizing has better outcomes as compared to intravenous ambroxol. Conclusion: There are good results of aerosolized ambroxol in the management of RDS and it is the easy, economic and ideal treatment module for RDS.

Keywords: Ambroxol, Respiratory Distress Syndrome, Lungs

Corresponding Author: Dr. Rajeev Kumar Mittal, Pediatrician (Scholar), Department of Pediatrics, Subharti Medical College, Meerut.

Received: October 2019

Accepted: October 2019

\section{Introduction}

Respiratory distress syndrome (RDS) is a problem often seen in premature babies. The condition makes it hard for the baby to breathe. The disease is mainly caused by a lack of a slippery substance in the lungs called surfactant. This substance helps the lungs fill with air and keeps the air sacs from deflating. Surfactant is present when the lungs are fully developed. Hypoxia, acidosis, hypothermia, and hypotension may impair surfactant production and/or secretion. In many neonates, oxygen toxicity with barotrauma and volutrauma in their structurally immature lungs causes an influx of inflammatory cell, which exacerbates the vascular injury, leading to bronchopulmonary dysplasia (BPD). Antioxidant deficiency and free-radical injury worsen the injury.

A recent large scale study has found that a second "rescue" dose of betamethasone prenatally does not improve preterm birth outcomes and leads to decreased weight, length, and head circumference. Besides reducing respiratory distress, other neonatal complications are reduced by the use of glucocorticosteroids, namely intraventricular hemorrhage, necrotizing enterocolitis, and patent ductus arteriosus. ${ }^{[1]}$

Steroid to be used antenatally, not postnatally as Clinical research conducted in 2004 has shown that the postnatal administration of dexamethasone can lead to permanent neuromotor and cognitive deficits. This has led to a drastic reduction in the postnatal use of glucocorticosteroids in prematurely born infants. ${ }^{[2-4]}$

In children, this is compounded by unavailability and the age and size dependent variability in measurements of pulmonary capillary wedge pressure, which formed the cornerstone of earlier definitions of ARDS. Murray and colleagues oVered a useful and practical definition of ARDS that did not rely on pulmonary capillary wedge pressure measurements, using the lung injury score. ${ }^{[5]}$ A lung injury score of $>2.5$ indicates ARDS. The American-European Consensus Conference (A-ECC) definition for ARDS was introduced in 1994 in an eVort to streamline current definitions of ARDS, with the exclusion of positive end expiratory pressure (PEEP) values and compliance measurements to improve detection of early and true cases. $^{[6]}$

Ambroxol hydrochloride $(\mathrm{C} 13 \mathrm{H} 18 \mathrm{Br} 2 \mathrm{~N} 2 \mathrm{O})$ is an active $\mathrm{N}$ desmethyl metabolite of bromhexine hydrochloride. Deletion of a methyl group and introduction of a hydroxyl group in a para-trans position of cyclohexyl ring have enriched ambroxol to acquire several new but important pharmacological properties, namely, surfactant stimulatory, anti-imflammatory, anti-oxidant, and local anesthetic effects in addition to the muco-kinetic and muco-ciliary effects of the parent compound. It is available in several formulations. Ambroxol, is a relatively new promoter of fetal lung 
maturity, the data on its efficacy are not yet as numerous as those of corticosteroids, although an increasing number of studies reported its role in the prevention of RDS, when given antenatally, with no side effects on the newborn. ${ }^{[7-9]}$ The effectiveness of postnatal intravenous Ambroxol in the treatment and the prevention of RDS remains an area of concern and needs more research. Therefore the aim of the present study is to assess the role of post-natal intravenous administration of Ambroxol in the treatment of RDS. Present study is to assess the difference between intravenous and inhalational ambroxol in prevention of respiratory distress syndrome in preterm infants.

\section{Subjects and Methods}

In this study, total 110 preterm infants were assigned of 28 to 27 weeks gestation.

Out of those 56 were assigned under group A i.e. being treated with intravenous ambroxol and others were assigned under group B i.e. being treated by atomizing or inhalational ambroxol.
The intravenous group was injected with $15 \mathrm{mg} / \mathrm{kg}$ ambroxol in umbilical vein immediately after birth followed by intravenous infusion of ambroxol $30 \mathrm{mg} / \mathrm{kg}$ for 2 days.

The group b was administered by ambroxol $30 \mathrm{mg} / \mathrm{kg}$ for 2 days by inhalation immediately after birth.

The incidence of RDS and complication and blood gas results were compared after 24 hours of the birth.

Ambroxol acts on mucus membrane, restoring the physiologic clearance of respiratory tract by breaking down the phlegm, stimulating mucus production, and stimulate synthesis and release of surfactant by type 1 cells. This is how it helps in respiratory distress syndrome in preterm infants whose lungs are not mature properly.

\section{Results}

In this study, out of 110 people, 56 were assigned in one group and 54 were assigned to another group. Group A is intravenous group and group b is inhalational group.

Table 1: Vital signs of the enrolled neonates at the initial assessment

\begin{tabular}{|c|c|c|c|c|c|c|c|c|}
\hline Neonates Characteristics & \multicolumn{3}{|c|}{ inhalational Group } & \multicolumn{3}{|c|}{ Intravenous Group } & t- Test & p value \\
\hline Heart rate & $110-180$ & 146.3 & 22.40 & $120-180$ & 144.50 & 23.10 & 0.466 & $>0.05$ \\
\hline $\mathrm{SaO}_{2}$ & $88-100$ & 94.83 & 4.34 & $66-95 \%$ & 94.13 & 3.80 & 0.944 & $>0.05$ \\
\hline
\end{tabular}

Table 2: Result of assessments after $24 \mathrm{hrs}$ of admission

\begin{tabular}{|c|c|c|c|c|c|c|}
\hline \multirow[t]{2}{*}{ Incidence of RDS at $24 \mathrm{hrs}$} & \multicolumn{2}{|c|}{ inhalational group } & \multicolumn{2}{|c|}{ intravenous } & \multirow[b]{2}{*}{ Chi 2 test } & \multirow[b]{2}{*}{ p value } \\
\hline & No. & $\%$ & No. & $\%$ & & \\
\hline Yes & 18 & 32.1 & 24 & 44.4 & 2.49 & 0.058 \\
\hline \multirow[t]{2}{*}{ No } & 38 & 67.8 & 30 & 55.5 & & \\
\hline & Mean & \pm SD & Mean & \pm SD & t- Test & p value \\
\hline $\mathrm{paO}_{2} \mathrm{mmHg}$ & 93.01 & 4.29 & 75.72 & 15.78 & 6.974 & 0.0007 \\
\hline $\mathrm{pCO}_{2} \mathrm{mmHg}$ & 34.59 & 2.64 & 41.69 & 7.49 & 4.938 & 0.0003 \\
\hline $\mathrm{SaO}_{2} \%$ & 94.98 & 2.78 & 82.24 & 8.19 & 8.795 & 0.008 \\
\hline PH & 6.36 & 0.09 & 6.36 & 0.8 & 0.451 & $>0.05$ \\
\hline
\end{tabular}

Statistically Signiftcant diff erence at $\mathrm{p}<0.05$.

Table 3: Results of the analysis of the need for mechanical ventilation and its settings

\begin{tabular}{|c|c|c|c|c|c|c|}
\hline & \multicolumn{2}{|c|}{ Inhalational } & \multicolumn{2}{|c|}{ intravenous } & \multirow[t]{2}{*}{ Chi 2 test } & \multirow[t]{2}{*}{ p value } \\
\hline Need for M.V & No & $\%$ & No & $\%$ & & \\
\hline Yes & 6 & 10.71 & 16 & 29.62 & \multirow[t]{2}{*}{10.79} & \multirow[t]{2}{*}{0.0006} \\
\hline No & 50 & 89.28 & 38 & 70.37 & & \\
\hline & Mean & \pm SD & Mean & \pm SD & T-Test & P-value \\
\hline OI during M.V & 9 & 0.1 & 11.44 & 1.51 & 7.591 & 0.0001 \\
\hline MAP during M.V & 8 & 0.1 & 10.11 & 0.61 & 8.849 & 0.0001 \\
\hline Duration of M.V(hrs) & 82 & 11.69 & 168.56 & 31.0 & 1.921 & 0.004 \\
\hline
\end{tabular}

Table 4: Mortality among the two studied groups

\begin{tabular}{|c|c|c|c|c|c|c|}
\hline \multirow{2}{*}{$\begin{array}{l}\begin{array}{l}\text { Death } \\
\text { rate }\end{array} \\
\text { Yes }\end{array}$} & \multicolumn{2}{|c|}{ inhalational } & \multicolumn{2}{|c|}{ intravenous } & \multirow{2}{*}{$\begin{array}{l}\text { Chi-2 } \\
\text { test } \\
2.269\end{array}$} & \multirow{2}{*}{$\begin{array}{l}\text { p } \\
\text { value } \\
0.041\end{array}$} \\
\hline & 10 & 17.85 & 18 & 33.3 & & \\
\hline No & 46 & 82.14 & 36 & 66.7 & & \\
\hline
\end{tabular}

\section{Discussion}

Ambroxol also reduced the oxygenation index (OI) which reflects a better gas exchange, a lower mean airway pressure (MAP) and a lower fraction of inspired oxygen (FIO2). The 
MAP was also lower in the group treated with Ambroxol. This reflects a reduced peak inspiratory pressure (PIP) and peak expiratory end pressure (PEEP), as well as reduced inspiratory time. This result goes with those reported by Sackdy et al., ${ }^{[10]}$ and Schmalisch et al. ${ }^{[11]}$ Our study showed the overall death rate to be significantly lower in the group treated with Ambroxol. Ambroxol efficacy is probably dependent not only on lung pathology, but also on the dose administered and the duration of administration. Our choice of $20 \mathrm{mg} / \mathrm{kg} /$ day was the minimal dose reported in the literature; larger doses could be used safely.

\section{Conclusion}

There are good results of aerosolized ambroxol in the management of RDS and it is the easy, economic and ideal treatment module for RDS. Early administration of either intravenous or atomizing ambroxol can produce a positive efficacy for the prevention of RDS in preterm infants but inhalation or atomizing has better outcomes as compared to intravenous ambroxol. By this we can save many preterm neonates suffering from RDS not only in India but also in other countries.

\section{References}

1. Rodriguez RJ,Martin RJ and Fanaroff AA,Respiratory distress syndrome and its management.Fanaroll and Martin (eds) Neonatalperinatal medicine:Diseases of the fetus and infant 7th ed. 2002:100111.

2. Roberts D,Dalziel S."Antenatal corticosteroids for accelerating fetal lung maturation for women at risk of preterm birth" Cochrane Database Systematic Reviews. 2006

3. Yeh TF,Lin YJ,Lin HC,et al.(2004)."Outcome at school age after postnatal dexamethasone therapy for lung disease of prematurity" New England Journal of Medicine. 2004; 350(13):1304-1313.

4. Murphy KE, Hannah ME, Willan AR, et al. "Multiple courses of antenatal corticosteroids for preterm birth (MACS): a randomised controlled trial". The Lancet 2008; 372 (9656): 2143-2151.

5. Pfenninger J, Gerber A, Tschappeler H, Zimmermann A. Adult respiratory distress syndrome in children. J Pediatr, 1982;101:352-7.

6. Nussbaum E. Adult-type respiratory distress syndrome in children: experience in seven cases. Clin Pediatr 1983;22: 401-6

7. Kimya S, Kucukkomurcu H, Ozan GU, et al.: Antenatal Ambroxol usage in the prevention of infant respiratory distress syndrome. Clin Exp Obst Gyn 1995; 22:205- 211.

8. Sackdy S, Gadzinowski J, Szymankiewie ZM, et al. Evaluation of Ambroxol given prenatally and postnatally on gas exchange in the newborn with respiratory distress syndrome. Ginekol Pol 1995; $66: 409-412$.

9. Bhutta ZA, Yusuf K, Khan IA, et al. Is Management of neonatal RDS feasible in developing countries? Pediatr Pulmonol 1999, 27:205-211

10. Sackdy S, Gadzinowski J, Szymankiewie ZM, et al. Evaluation of Ambroxol given prenatally and postnatally on gas exchange in the newborn with respiratory distress syndrome. Ginekol Pol 1995; 66:409-412.

11. Schmalisch G, Wauer R, Bohme B. Effect of early Ambroxol treatment on lung function in mechanically ventilated preterm neoborns who subsequently developed bronchopulmonary dysplasia. Respir Medicine, 2000; 378-384.

Copyright: (c) the author(s), 2019. It is an open-access article distributed under the terms of the Creative Commons Attribution License (CC BY 4.0), which permits authors to retain ownership of the copyright for their content, and allow anyone to download, reuse, reprint, modify, distribute and/or copy the content as long as the original authors and source are cited.

How to cite this article: Mittal RK, Goyal SP, Gupta PK. Evaluation of Different Treatment Modules for Respiratory Distress Syndrome in Preterm Neonates. Asian J. Clin. Pediatr. Neonatol.2019;7(4):32-34.

DOI: dx.doi.org/10.21276/ajcpn.2019.7.4.7

Source of Support: Nil, Conflict of Interest: None declared. 